\title{
Do teatro da resposta ao teatro da interrogação
}

\author{
Miguel Falcão
}

\section{Glória Bastos, $O$ teatro para crianças em Portugal: História e crítica, Lisboa, Caminho, 2006, 387 pp.}

0 teatro "para crianças" ou "para a infância" em Portugal tem vindo a desvincular-se, a pouco e pouco (e com passos mais largos nas últimas três décadas), das ideias redutoras de divertimento ingénuo e descomprometido ou de "teatro para adultos simplificado" (Wood / Grant 1997: 5). Alguns autores dos textos dramáticos, a par de diversas estruturas de criação teatral, têm tido um papel fundamental na evolução desse entendimento, de que é paradigmático o testemunho do dramaturgo José Jorge Letria: "por ser feito para os mais jovens não deve desresponsabilizar quem o faz, mas, pelo contrário, criar uma acrescida responsabilidade. É que, quem escreve para as crianças, ao divertir e entreter, também forma, porque lança sementes de interrogação e de inquirição que podem contribuir para aguçar a vocação crítica de sensibilidades e de consciências" (Letria 1994: 67-68). Mas nem sempre foi assim. Aliás, ainda hoje nem sempre é assim.

Nas obras de âmbito historiográfico sobre o Teatro em Portugal, não encontramos, a não ser em casos raros, mas de forma dispersa e sucinta, informação aprofundada, fundamentada, sistematizada e interpelada - relativa a este território específico, que permita alargar o conhecimento sobre contextos de criação, criadores e peças, bem como perspectivar, criticamente, linhas de continuidade e de ruptura.

Esse empreendimento surge, finalmente, exaustivo e rigoroso, pela mão de Glória Bastos, investigadora e professora de Literatura, a quem já deviamos, entre outras obras, A escrita para crianças em Portugal no século XIX (Caminho, 1997) e, em co-autoria com Ana Isabel Vasconcelos e José Carlos Alvarez, 0 teatro em Lisboa no tempo da Primeira República (Museu do Teatro, 2004). Com esta obra, que resulta da adaptação para publicação da sua tese de doutoramento, a autora pretende traçar, como define claramente na introdução, "um percurso histórico e crítico que procurará identificar e compreender correntes e finalidades de escrita, interacções culturais e literárias, bem como as dominantes temático-estilisticas mais marcantes" (p. 31).

Embora o seu estudo incida na escrita dramática é docente da Escola Superior de Educação de Lisboa / publicada em livro (como recorrentemente ressalva), a autora não aliena a preocupação de relacionar, com regularidade, as peças que vai inventariando com os contextos e as estruturas, bastante diferenciados, de

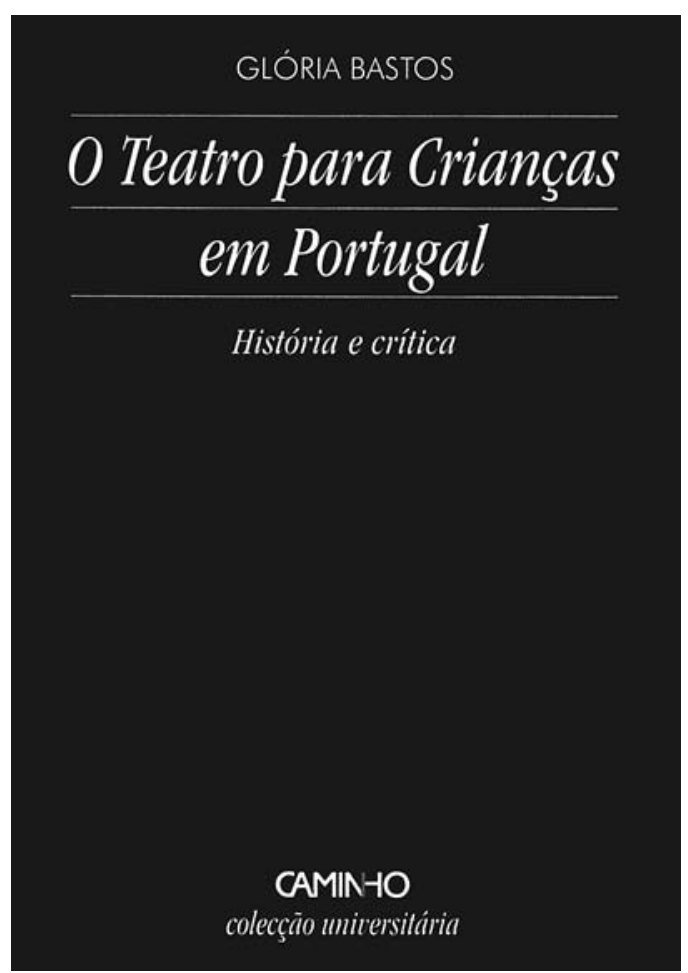

criação cénica, facto em que, de algum modo, se poderá ver uma legitimação do termo escolhido para o título da obra: "teatro" e não "dramaturgia". De resto, para melhor contextualizar o surgimento dos textos dramáticos, a autora sentiu a necessidade, logo à partida, de rever o conceito genérico de "teatro infantil", ele próprio objecto de múltiplas versões ao longo dos tempos e sempre envolto em controvérsia, que cruza a vertente da escrita dramática com a da criação teatral. E, neste sentido, procura compreender não só a esfera do destinatário (apesar de tudo mais consensual), mas, sobretudo, a dos emissores, sintetizável nesta triade de perspectivas: (i) teatro escrito e representado por crianças; (ii) teatro escrito por adultos e representado por crianças; e (iii) teatro escrito e representado por adultos (p. 28).

0 reconhecimento destas perspectivas insere-se num programa de estudo, mais vasto e ambicioso, que procurou diagnosticar e analisar os entendimentos especificos sobre texto dramático e teatro para crianças, na dupla vertente da conceptualização e da concretização. A identificação das principais marcas distintivas conduziu a autora à partição de pouco mais de cem anos em três fases, 
sinalizando, em cada uma, "núcleos de produção" metaliterária, teatral e dramática, destes distinguindo os dramaturgos - e, numa das épocas, duas companhias que considerou paradigmáticos de um modo epocal de sentir e cumprir a escrita e o espectáculo.

A Parte I, "Os primeiros tempos" (pp. 35-98), encontrase balizada entre o final do século XIX, uma vez que, como defende, "nas épocas anteriores a esse século, muito dificilmente se pode falar, em geral e mais concretamente no caso português, de teatro infantil na sua acepção de especificamente 'para crianças'"' (p. 33), e o fim da Primeira República. Neste periodo, assiste-se à valorização do livro como instrumento da educação das crianças e, também, da dimensão educativa do "teatro infantil", para e com crianças, privilegiadamente no território escolar. Maria Rita Chiappe Cadet é destacada pelo seu pioneirismo na publicação de textos dramáticos para crianças, caracterizados, de forma genérica, por uma tentativa de balancear o divertimento e a instrução, resvalando claramente para o tom moralizador com que visa (en)formar "crianças exemplares", obviamente das classes socialmente favorecidas.

A Parte II, "No tempo do Estado Novo" (pp. 99-222), percorre as mais de quatro décadas da ditadura salazarista (/caetanista), globalmente caracterizada, por um lado, por uma forte repressão censória, que interferiu negativa e irremediavelmente nos processos de criação artística, $\mathrm{e}_{\text {, }}$ por outro, na instrumentalização do teatro, também para crianças, pelo regime. Nesta conjuntura, pela "qualidade dos textos publicados", pelo papel desempenhado "na divulgação do acto teatral junto do público infantil e juvenil" e por serem as "duas únicas manifestações consistentes de um teatro profissional, realizado por adultos, para crianças" (p. 102), sobressaíram a Companhia Amélia Rey Colaço/Robles Monteiro no Teatro Nacional, entre os finais dos anos 30 e a década de 50, e o Teatro do Gerifalto (1956-1973), projecto que em vários aspectos deu continuidade ao institucional Teatro da Mocidade (1948-1958), ambos impulsionados e dinamizados por António Manuel Couto Viana, empresário e dramaturgo empenhado no teatro para este público específico.

A Parte III, "Mudam-se os tempos..." (pp. 223-308), abarca os últimos trinta anos, neles se destacando o aparecimento de novos autores e a consequente multiplicidade de vozes criadoras, a abertura do mercado editorial e o forte investimento na edição em livro, também de textos dramáticos para crianças, a criação de prémios e outros incentivos e o surgimento de várias companhias teatrais, também profissionais, vocacionadas para o público infanto-juvenil. De um conjunto de mais dificil escolha, onde pontuam nomes como os de Manuel António Pina, Maria Alberta Menéres, Orlando Neves, Jaime Salazar Sampaio, Maria Rosa Colaço ou Teresa Rita Lopes, entre tantos outros, a autora destaca António Torrado, não só pela sua consagração como escritor, mas sobretudo pela sua faceta de "pedagogo preocupado" e de dramaturgo inventivo, que "não esquece o real e uma subtil reflexão centrada nos problemas fulcrais da dimensão social" ( $p$. 290).

Destacamos três aspectos da evolução do texto dramático, ao longo das épocas estudadas:

- A progressão de uma representação realista para uma representação "fantasista", verificando-se, sobretudo no pós-Abril (embora com génese ainda na década de 60, em peças de Norberto Ávila, Ilse Losa, Maria Isabel Mendonça de Soares ou Isabel da Nóbrega), a opção clara por experiências de renovação temática e formal e pela complexificação interpretativa, que, designadamente através de personagens da "fantasia moderna" ("animais humanizados" ou "ficção científica", por exemplo), se distanciaram, assumidamente, das situações familiares "caseiras" e das boas condutas na escola da "verdade", no período entre o fim do século XIX e a Primeira República, bem como da obsessão estado-novista pela memória histórica e pela exaltação dos "heróis" nacionais;

- A passagem de um discurso afirmativo a um discurso da dúvida, que, tanto ao nível da macroestrutura e dos processos formais de escrita, como dos diálogos entre as personagens, desvela a oposição entre um discurso argumentativo e exortativo (eficaz na transmissão ideológica de "certezas" e de "autoridade") e um discurso democratizante, no qual há lugar para o questionamento e para as interacções igualitárias;

- A evolução de uma pedagogia "visível" para uma pedagogia "invisível", facto que confirma a permanente adequação da mensagem e dos modos de a transmitir à natureza dos vários regimes políticos, e, por conseguinte, a diferenciadas matrizes ideológicas, revelando-se ora mais delimitados e explícitos, ora mais amplos e implícitos, tendo em 1974 um marco histórico que separa perspectivas tão dispares, como valores oficiais e obrigatórios de visões particulares do mundo, unanimidade de pluralidade.

Como bem assinala Glória Bastos, se, por um lado, só após o 25 de Abril de 1974 se começou a assistir a uma progressiva autonomização da literatura dramática e do teatro em relação à escola (terreno, sempre privilegiado, 
$<>$

Os piratas,

de Manuel António Pina,

enc. João Luiz,

Teatro Pé de Vento, 1987

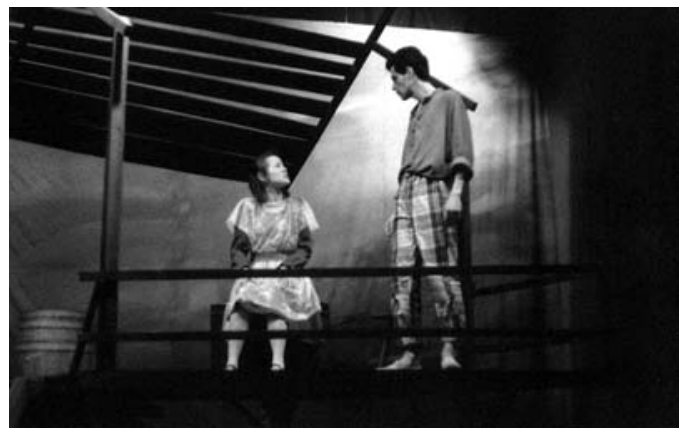

para uma mais ou menos explícita modelação, quando não doutrinação), por outro lado, a sua inscrição numa perspectiva pedagógica tem sido contínua, acompanhando os movimentos da educação contemporânea e a evolução dos estudos sobre a criança. Esta verificação leva a autora a concluir que, "sobretudo nos textos com maior complexidade artística, tem-se conseguido suscitar o interesse, emocionar e informar, sem cair nos perigos do didactismo" (p. 317). Recorrendo a casos como o do dramaturgo António Torrado, que em certos aspectos encontra eco em práticas teatrais, de que destaca o projecto de 0 Bando, a autora defende que estamos na presença não só de uma "maturidade dramatúrgica" (que investe na renovação das formas e das estruturas), mas também da emergência de uma "visão nova do leitor/espectador modelo". As relações que, hoje, se estabelecem entre estes três universos focados (dramaturgia, criação teatral e escola/sistema educativo), suscitam três considerações finais.

A primeira é referente à distância, que tende a acentuar-se, entre um entendimento tradicional da escrita dramática para crianças, que, aliás, como fica comprovado, continua a preferir, persistentemente nas diferentes épocas estudadas, uma estrutura de progressão linear, designada pela autora por "modelo supra-existente" (p. 315), e aquilo a que Eugénia Vasques, no texto com que prefacia esta obra, designa por "ideia de 'escrita cénica' assumida pelas novas gerações e pelas linguagens da contemporaneidade" (p. 16).

Em segundo lugar, não pode deixar de ser referida a insistência, por parte de muitos fazedores (com excepções, que Glória Bastos também identifica), na opção por textos convenientes e na repetição de fórmulas, repisadas e estafadas, como garantia de sucesso. Estes factores, e outros (como o encafuamento nas salas de um número de crianças muito superior ao que seria desejável, por razões de rentabilização económica, que, todavia, compromete as condições de recepção e fruição do espectáculo), não só constrangem a "dimensão comunicativa do teatro" e a sua "função socializadora", nos quais a autora coloca a tónica, como substituem ou prorrogam, potencialmente, aspectos desde sempre promotores da "infantilização" do teatro para crianças.

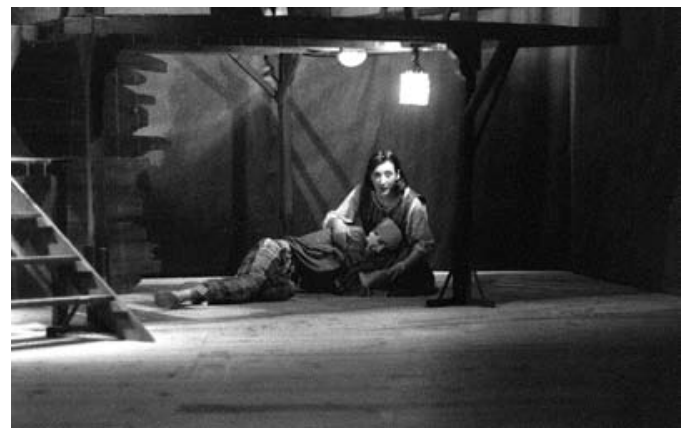

Por último, uma palavra sobre a dissonância entre este novo e feliz cenário no plano da dramaturgia, verificado por Glória Bastos, e a vivência do teatro - e em particular do texto dramático - pelas crianças no seu quotidiano escolar. Procurando passar ao largo da questão, gravíssima e sub-reptícia, do actual progressivo afastamento das artes - em geral, e em particular do teatro - dos currículos dos ensinos básico e secundário, atente-se no tratamento que é dado ao texto dramático, designadamente no $1^{\circ} \mathrm{e}$ no $2^{\circ}$ ciclos de escolaridade (correspondentes à faixa de público em apreço). Dois exemplos são paradigmáticos: em muitas bibliotecas escolares, apesar do grande investimento dos últimos anos e da sua crescente qualidade, as secções destinadas ao texto dramático são inexistentes ou, na melhor das hipóteses, infimas (e pouco representativas da dramaturgia actual); e nos manuais escolares, sobretudo do $1^{\circ}$ ciclo, o texto dramático, quando surge, é frequentemente reduzido a meia dúzia de linhas, as mais das vezes inventadas pelos próprios autores para ilustrarem a estrutura em falas e didascálias, e nem sempre mobilizando os conceitos com correcção. Esta realidade - há que (re)conhecê-la para se Ihe fazer face - condiciona fortemente o acesso das crianças ao objecto, cuja maioria não se move em ambientes familiares promotores de leitura.

Esta obra, profundamente documentada, lança pistas, também, para uma compreensão destes fenómenos, para além de apresentar um "repertório de peças publicadas" (Anexo, pp. 355-379), no qual inventaria mais de mil títulos de trezentos e cinquenta dramaturgos, de 1883 a 2005 , que muito úteis poderão ser aos universos teatral e educativo (/escolar). Mas o contributo de Glória Bastos terá de ser entendido de modo mais amplo, devendo reconhecer-se-Ihe que, com esta obra, vem preencher as páginas sobre a dramaturgia para crianças, reiteradamente por escrever, das nossas Histórias do Teatro em Portugal.

\section{Referências bibliográficas}

LETRIA, José Jorge (1994), Do Sentimento Mágico da Vida, Lisboa, Editorial Escritor.

WOOD, David / GRANT, Janet (1997), Theatre for Children, London, Faber and Faber. 